\title{
Comparison of predictions of digestible supply and measurements of net portal fluxes of essential amino acids in lactating dairy cows*
}

\author{
D. Pacheco ${ }^{1}$ and H. Lapierre \\ Agriculture and Agri-Food Canada, \\ Dairy and Swine Research and Development Centre \\ 2000 Route 108 East, Lennoxville, Québec, J1M 1Z3. Canada
}

\begin{abstract}
Estimated digestible amino acids (AA: corrected for endogenous secretions) obtained from the NRC and CNCPS models appear to be good predictors of the AA profile flowing into the portal vein. However, for absolute amounts, the NRC model more closely predicts the changes measured in net portal fluxes compared to the CNCPS. The slopes of the regression "AA net portal flux vs AA digested-NRC" are in agreement with AA metabolism across the gut: slope smaller that unity indicating loss for the branched-chain AA (oxidation) and for Thr (endogenous loss); slope equal to unity for Lys, indicating little loss. Slopes greater than unity for His, Met and Phe suggest either an underestimation of the digestible flow with the NRC model or an overestimation of the net portal fluxes for these AA.
\end{abstract}

KEY WORDS: amino acids, dairy cows, prediction models, net portal fluxes

\section{INTRODUCTION}

Mathematical models have been designed to estimate the requirements and productive responses of lactating dairy cows (e.g., Cornell Net Carbohydrate and Protein System (CNCPS v. 5.0.34) and National Research Council (NRC, 2001). These models rely on empirical relationships between metabolizable protein (i.e. absorbed amino acids) and milk protein output, without taking into account metabolic events occurring in the portal-drained viscera (PDV) and the liver. Hence, our current research seeks for ways to improve the accuracy of whole-

\footnotetext{
* Supported by Dairy Farmers of Canada

${ }^{1}$ Present address: AgResearch Ltd. Private Bag 11 008, Palmerston North, New Zealand

${ }^{1}$ Corresponding author: e-mail: david.pacheco@agresearch.co.nz
} 
animal models by including mechanistic elements to take into account the events to which essential amino acids (EAA) are subjected to during their transfer from duodenum to the mammary gland.

A first step in our modelling approach was to estimate net portal fluxes of EAA using predictions of digestible EAA flow from two models: CNCPS and NRC. Our objective was to compare measurements of net portal fluxes of EAA in dairy cows against predicted digestible EAA, to determine which of the two models could be used as a starting point for a mechanistic model of EAA utilization in dairy cows.

\section{MATERIAL AND METHODS}

Eight treatment means for net portal fluxes were obtained from the studies conducted by our group (Berthiaume et al., unpublished; Lapierre et al., unpublished; Raggio et al., 2004). Feedstuffs included in the diets in these trials were individually analysed for chemical composition, including the CNCPS fractions and AA. Data from the ingredient analyses $(n=33)$, ration formulations and average intakes from each treatment were entered into the CNCPS (version 5.0.34) and NRC (2001) software packages to obtain estimates of AA flows to duodenum. To allow a direct comparison with the net portal flux measurements, estimated digestible AA flows to duodenum were corrected by subtracting the endogenous secretions as specified for each model. Linear regression analysis of portal fluxes $(y)$ on the estimated duodenal flows $(x)$ served as an indicator of the degree of association between the two variables. Regression analyses were performed using the REG procedure from SAS with the NOINT option. Differences between AA profiles in portal and digestible flows were assessed by performing a correspondence analysis (CORRESP procedure) in SAS.

\section{RESULTS}

Digestible supply of EAA estimated by CNCPS were numerically higher ( 5 to $40 \%$ higher) than those obtained from the NRC model, with exception of leucine, which was only $92 \%$ of the NRC value (Table 1 ). The estimated digestible EAA flows are, on average, 103 and $118 \%$ of the measured net portal fluxes for the NRC and CNCPS, respectively. However, the ratio of digestible flow to net portal flux for individual EAA ranged from 82 (Met) to $129 \%$ (Arg). The amounts estimated by NRC and CNCPS models were numerically lower than the net portal flux for Phe (87 and $91 \%$, respectively).

The analysis of correspondence indicated that AA profiles are not different between portal measurement and NRC and CNCPS estimations $\left(\mathrm{P}>0.05 \chi^{2}\right.$ test, 16 df). The first principal axis (54\% of the dataset inertia) is a contrast between the 
results from NRC (higher Leu) and CNCPS models (higher Arg and His); while the second principal axis ( $46 \%$ of inertia) highlights a contrast between the net portal fluxes (higher Phe and Met) and the two models for estimation of digestible AA (higher Thr).

Table 1. Amino acid (AA) amounts (g/d) and profiles (\% of essential amino acids) from measured net portal fluxes, or from estimation of digestible AA by the NRC 2001 and CNCPS 5.0 models

\begin{tabular}{|c|c|c|c|c|c|c|}
\hline \multirow[b]{2}{*}{ EAA } & \multicolumn{2}{|c|}{ Net portal flux measured } & \multicolumn{2}{|c|}{ NRC estimation } & \multicolumn{2}{|c|}{ CNCPS estimation } \\
\hline & mean $\pm \mathrm{SD}$ & $\begin{array}{l}\% \text { of } \\
\text { EAA }\end{array}$ & mean $\pm \mathrm{SD}$ & $\begin{array}{l}\text { \% of } \\
\text { EAA }\end{array}$ & mean $\pm \mathrm{SD}$ & $\begin{array}{l}\% \text { of } \\
\text { EAA }\end{array}$ \\
\hline Arg & $89 \pm 16.2$ & 11.2 & $82 \pm 13.1$ & 10.1 & $115 \pm 14.3$ & 12.9 \\
\hline His & $43 \pm 10.6$ & 5.4 & $40 \pm 8.5$ & 5.0 & $52 \pm 7.4$ & 5.9 \\
\hline Ile & $83 \pm 13.9$ & 10.5 & $85 \pm 11.0$ & 10.5 & $94 \pm 9.8$ & 10.6 \\
\hline Leu & $147 \pm 31.1$ & 18.6 & $170 \pm 26.0$ & 21.0 & $157 \pm 19.5$ & 17.6 \\
\hline Lys & $119 \pm 20.9$ & 15.1 & $116 \pm 19.7$ & 14.4 & $129 \pm 16.1$ & 14.5 \\
\hline Met & $41 \pm 8.7$ & 5.2 & $34 \pm 5.5$ & 4.2 & $44 \pm 4.8$ & 4.9 \\
\hline Phe & $106 \pm 23.4$ & 13.4 & $91 \pm 14.5$ & 11.2 & $95 \pm 11.2$ & 10.6 \\
\hline Thr & $69 \pm 15.3$ & 8.8 & $85 \pm 12.1$ & 10.5 & $93 \pm 10.8$ & 10.4 \\
\hline Val & $93 \pm 18.9$ & 11.7 & $105 \pm 17.3$ & 13.1 & $113 \pm 14.0$ & 12.7 \\
\hline
\end{tabular}

Table 2. Regression analysis using the NRC and CNCPS estimated digestible EAA as predictors of net portal flux ${ }^{1}$

\begin{tabular}{llcccc}
\hline \multirow{2}{*}{ EAA } & \multicolumn{2}{c}{ NRC } & & \multicolumn{2}{c}{ CNCPS } \\
\cline { 2 - 3 } \cline { 5 - 6 } \cline { 5 - 6 } & Slope $(\mathrm{SE})$ & RMSE $^{2}$ & & Slope $(\mathrm{SE})$ & RMSE \\
\hline Arg & $1.11(0.07)$ & 11.06 & & $0.82(0.09)$ & 19.74 \\
His & $1.07(0.03)$ & 3.37 & & $0.82(0.05)$ & 7.51 \\
Ile & $0.97(0.05)$ & 11.56 & & $0.87(0.06)$ & 15.60 \\
Leu & $0.87(0.05)$ & 22.46 & & $0.93(0.07)$ & 31.33 \\
Lys & $1.02(0.03)$ & 9.59 & & $0.92(0.04)$ & 14.66 \\
Met & $1.22(0.04)$ & 3.76 & & $0.95(0.06)$ & 5.94 \\
Phe & $1.17(0.04)$ & 10.33 & & $1.13(0.06)$ & 15.36 \\
Thr & $0.82(0.04)$ & 8.65 & & $0.75(0.04)$ & 11.66 \\
Val & $0.88(0.03)$ & 8.99 & & $0.82(0.04)$ & 14.40 \\
\hline
\end{tabular}

${ }^{1}$ equations are in the form Net portal flux, $\mathrm{g} / \mathrm{d}=$ Slope $\times$ digestible flow, $\mathrm{g} / \mathrm{d}$

${ }^{2}$ root mean square error: smaller value indicates better fit. SE: standard error of the estimate

As expected, for both models the slopes of the regression "net portal flux vs digestible flows" indicate that for all EAA net portal flux has a positive linear association with digestible flow. The NRC model estimates yielded lower root mean square errors when used to explain the changes in net portal flux (Table 2) compared to the CNCPS. For the NRC estimates, His, Met and Phe slopes were significantly $(\mathrm{P}<0.05)$ greater than unity. For CNCPS, the same situation arises for Phe $(\mathrm{P}=0.06)$. 


\section{DISCUSSION}

Although the values originate from totally different approaches (arterio-venous differences for net portal fluxes vs mathematical models for digestible flows), they relate very closely.

For most EAA, the value of the slope of the regression of net portal flux vs digestible flow from NRC is in agreement with expected metabolism of the EAA across the PDV (Berthiaume et al., 2001; Lobley and Lapierre, 2003). A slope less than unity would indicate loss across the PDV (e.g., oxidation for the branched chain AA, endogenous loss for Thr). A slope equal to unity would indicate very little catabolism for Lys. For His, Met and Phe, the slopes greater than unity indicate marginal increases in net portal flux that are greater than the digestible flow for these EAA, suggesting underestimation of the digestible flow by NRC or overestimation of the net portal flux measurements.

Estimated digestible flows from CNCPS were higher than NRC, but this model fails to follow the pattern of changes in net portal flux, as indicated by its higher RMSE values for all EAA. Also, the slopes for individual EAA do not reflect the differential metabolism of EAA across the gut as well as those calculated from NRC estimations.

\section{CONCLUSIONS}

Digestible flows of EAA estimated with NRC better predict the measured changes in net portal fluxes of EAA in lactating dairy cows.

\section{REFERENCES}

Berthiaume R., Dubreuil P., Stevenson M., McBride B.W., Lapierre H., 2001. Intestinal disappearance and mesenteric appearance of amino acids in dairy cow fed ruminally protected methionine. J. Dairy Sci. 83, 765-775

Cornell Net Carbohydrate and Protein System, Version 5.0.34. Cornell University, Ithaca, NY

Lobley G.E., Lapierre H., 2003. Post-absorptive metabolism of amino acids. In: W.B Souffrant, C.C. Metges (Editors). Progress in Research on Energy and Protein Metabolism. Wageningen Academic Publishers, Wageningen (The Netherlands), pp. 737-756

National Research Council, 2001. Subcommittee on Dairy Cattle Nutrition. Nutrient Requirements of Dairy Cattle. $7^{\text {th }}$ revised Edition. National Academy Press, Washington, DC

Raggio G., Pacheco D., Berthiaume R., Lobley G., Pellerin D., Allard G., Dubreuil P., Lapierre H., 2004. Effect of level of metabolizable protein on splanchnic flux of amino acids in lactating dairy cows. J. Dairy Sci. (in press) 